\title{
POLÍTICA DE INCENTIVO À LEITURA NO GOVERNO ZAIRE REZENDE (1983-1988)
}

\author{
Márcia Cicci Romero ${ }^{1}$ \\ Sônia Maria dos Santos ${ }^{2}$
}

\begin{abstract}
RESUMO
Essa pesquisa teve como objetivo geral analisar as propostas chamadas de Políticas culturais do governo de Zaire Rezende realizadas no período de 1983-1988 na cidade de Uberlândia/MG. A ideia inicial foi coletar materiais que possibilitassem mapear as propostas que deram subsídios ao desenvolvimento de políticas culturais, especialmente àquelas ligadas ao incentivo da leitura. Os objetivos específicos foram: identificar como as políticas culturais de Leitura do governo de Zaire Rezende foram implementadas e como chegaram à população de baixa renda; identificar e entrevistar quais foram os sujeitos responsáveis pela implementação das políticas de leitura do governo de Zaire Rezende; investigar como se deu a reinauguração da Biblioteca Municipal "Juscelino Kubitschek de Oliveira" nesse mesmo governo. Trata-se de uma pesquisa qualitativa, cuja metodologia pautou-se na História Oral Temática. As entrevistas realizadas propiciaram ouvir e analisar se a população realmente teve espaço dentro do governo intitulado de "democracia participativa" para realizar suas reivindicações, sendo uma delas a leitura. O estudo mostrou como a população de baixa renda vivenciou um processo chamado de democracia participativa, modelo esse diferente, do tradicional, do qual tiveram anseios atendidos.
\end{abstract}

Palavras-chave: História Oral; Governo Zaire Rezende; Política de Leitura.

\section{POLICIES OF INCENTIVE THE READING IN GOVERNMENT ZAIRE REZENDE (1983-1988)}

\begin{abstract}
This research aimed to map the bids called Cultural Policies of Zaire Rezende's government held in the period from 1983 to 1988 in the city of Uberlândia/MG. The initial idea was to collect materials that would enable mapping out the bids that gave subsidies to the development of cultural policies, especially those related to reading incentive. The specific objectives were: to identify how the cultural policy of Zaire Rezende's government towards reading have been implemented and how they arrived to low-income population; to identify and interview which were the subjects responsible for implementing government reading policies of Zaire Rezende; to investigate in which circumstances the reopening of the Municipal Library "Juscelino Kubitschek de Oliveira" took place, in that same government. It is a qualitative research whose methodology was based on the genre of Thematic Oral History. The interviews led to ascertain whether the population actually had space within the government entitled "participatory democracy" to make their demands, one of them reading. The study showed how a low-income population experienced a process called participatory democracy, a model that was different from the traditional one, which had some of their desires met.
\end{abstract}

Keywords: History oral; Government Zaire Rezende; Policies Reading 
Para analisar a política cultural de leitura fizemos uma releitura do contexto político e social do período de 1983 a 1988. Neste contexto descobrimos que o fim da ditadura militar trouxe a baila vários problemas para a pauta dos governantes do país, dentre eles estavam a economia, a educação, a política, a pobreza, a moradia e o saneamento básico, incluindo pouquíssimos investimentos na área da cultura. O município de Uberlândia localizado no interior de Minas Gerais na região do Triângulo Mineiro, teve um candidato cujo nome é Zaire Rezende, o qual apresentou uma carta de intenções para o período de 1983 a 1988 contendo uma proposta diferente e um tanto inusitada para o período pós ditadura. Nas narrativas dos sujeitos entrevistados descobrimos que a equipe que elaborou a proposta de governo trouxe no seu bojo, como uma das principais preocupações as questões relacionadas à cultura, sendo que, dentre os desafios, da proposta de governo foi possível encontrar a que referia a leitura da população uberlandense.

Escolhemos a História Oral como método de pesquisa, pois ela nos auxiliou a compreender e analisar como a primeira gestão do governo municipal denominado de Zaire Rezende (1983-1988) pela população uberlandense se concretizou, pois, seu governo aconteceu no período de transição democrática. Foi nesse processo ainda turbulento e de recessões, inclusive no campo da cultura, que a proposta de governo dita "democrática" pela equipe de trabalho trouxe como desafio para o gestor municipal, criar e desenvolver projetos, especialmente na Biblioteca Pública Municipal da cidade de Uberlândia, cuja meta era incentivar a cultura e a leitura. Dessa forma, as entrevistas realizadas, transcritas e utilizadas na dissertação de mestrado, a qual deu origem a esse artigo permitiram que os sujeitos pudessem atribuir uma ressignificação do que foi vivenciado e experimentado, como também aos próprios fazeres neste governo, já que por meio das entrevistas a memória remete o narrador ao passado, e suas histórias tornam-se históricas.

Neste estudo foi importante compreender a relevância da História Oral e o lugar das narrativas, nas pesquisas qualitativas, pois ela nos fez estudar questões importantes tanto no que se refere a história como também a memória. As entrevistas nos possibilitaram, compreender como a memória é ativada, e como o sujeito narra e reconstrói uma história vivenciada e experimentada. Sendo assim a entrevista nos possibilitou, apropriar de uma escuta sensível, daqueles que pensaram e executaram o projeto de governo. Momento esse importante o qual descobrimos que:

A memória é um processo individual, que ocorre em um meio social dinâmico, valendo-se de instrumentos socialmente criados e compartilhados. Em vista disso, as recordações podem ser semelhantes, contraditórias ou sobrepostas. Porém, em hipótese alguma, as lembranças de duas pessoas são - assim como as impressões digitais, ou, a bem da verdade, como as vozes - exatamente iguais (PORTELLI, 1997b, p. 16).

Neste contexto de configurar o lugar da memória na História Oral é importante registrar neste texto que ela possui três possibilidades dentre as quais foram denominadas de história de vida, a tradição oral e a história temática. Neste estudo escolhemos a história oral temática, pois, acreditamos que ela nos aproximou do objeto e dos sujeitos, que trabalharam na biblioteca municipal e na Secretaria de Cultura.

Para Meihy a, 
História Oral Temática, por sua vez, está mais vinculada ao testemunho e à abordagem sobre algum assunto específico. A vida enquanto experiência individual tem, para esta vertente, significado menor e relativo. A História Oral Temática é um recorte da experiência como um todo e quase sempre - ainda não obrigatoriamente -, concorre com a existência de pressupostos já documentados e parte para "uma outra versão". Em alternativa diversa colabora para o "preenchimento dos espaços vazios nas versões estabelecidas" (MEIHY, 1993, p. 57).

A escolha dos sujeitos que foram entrevistados se deu por meio de idas ao Arquivo Público de Uberlândia e à Biblioteca Pública Municipal Juscelino Kubitschek de Oliveira. A primeira visita foi à biblioteca, na qual foi possível encontrar com a diretora da mesma, e na ocasião foi explicado sobre o tema e o problema deste estudo. Ela relatou que começou a trabalhar na biblioteca no governo de Zaire Rezende e marcou horário para outra visita. Carvalho tinha no período da construção da dissertação 52 anos e era uma bibliotecária formada pela Escola de Biblioteconomia da Universidade Federal de Minas Gerais (UFMG) com Pós-Graduação e especialização em Administração de bibliotecas públicas e escolares pela Universidade de Brasília (UNB).

O segundo sujeito entrevistado para o estudo foi o ex-prefeito Zaire Rezende. Foi possível encontrá-lo nos corredores da Universidade Federal de Uberlândia, exatamente no bloco G, prédio onde está instalada a FACED (Faculdade de Educação) e onde ocorrem as aulas do PPGED (Programa de Pós-Graduação em Educação). Ele estava fazendo o curso de filosofia. Zaire Rezende nasceu no dia 25/12/1931, tem 84 anos, é médico, filósofo e político. Formado em Medicina, tendo exercido a profissão até 1982, período das eleições municipais, formado também em 1974 pela Faculdade Católica no curso de Filosofia.

A descoberta do terceiro sujeito entrevistado se deu pelas idas ao Arquivo Público, uma funcionária indicou a ex-chefe da biblioteca, Silva, para ser entrevistada. Silva tinha 59 anos, era bibliotecária, atualmente é analista legislativa bibliotecária. Tem mestrado, doutorado e pós-doutorado em Ciência da Informação. Foi solícita para receber a pesquisadora, como também para ser entrevistada e ficou feliz ao ver algumas fotos que encontramos no Arquivo Público pois ela já tinha trabalhado na biblioteca.

A quarta entrevistada foi a ganhadora do concurso da biblioteca "Descubra o contador de histórias do seu bairro". A indicação foi de Carvalho. Mendonça tinha 55 anos, conhecida na cidade como Vovó Caximbó, é contadora de histórias e atriz, coordenadora do Grupo Faz de Conta e possui segundo grau completo.

A última narradora foi indicação da funcionária do Arquivo Público. Torres, que trabalhava na Secretaria de Cultura até o momento deste estudo. Ela tinha 56 anos, é formada em Letras/Português-Francês e História pela UFU. Possui uma especialização em Literatura Brasileira Contemporânea e outra em Gestão Cultural.

As narrativas dos sujeitos entrevistados ilustram como o desejo e o empenho que o grupo gestor teve para que os planos políticos pudessem ser concretizados. Carvalho afirma que "foi extremamente produtiva, todo mundo queria que desse certo, queria fazer acontecer, e aconteceu, e a gente tem boas lembranças daquela época” (ROMERO, 2015, p.190).

Para Torres: "Muita vontade de fazer acontecer e a gente se misturava para fazer acontecer!" (2015, p. 222). A vontade para que os projetos e os planos dessem certo das pessoas que trabalhavam juntas tanto da Biblioteca Pública Municipal como da Secretaria de Cultura da época era intenso e exigia participação coletiva do grupo gestor. As narrativas nos remetem ao espírito de equipe do grupo todo, já que as ideias eram muitas e os esforços não eram medidos para que todos os projetos pudessem ser concretizados, as 
narrativas revelam um certo saudosismo e passam mais a ideia dos acertos do que dos erros ou equívocos que a gestão possa ter cometido.

Neste contexto podemos afirmar que é pela história que a memória encontra subsídios para formar-se, e é dessa forma que o presente pode ser interpretado com base no passado. Passado e presente possuem uma relação histórica, já que é o presente que impõe certas necessidades para o povo que vê a necessidade de lembrar o passado para compreender um objeto histórico. A identidade é, então, um fenômeno de um grupo social, de uma existência coletiva em diferentes períodos históricos e que pelo sentimento é expressada como referência ou pelo sentimento de pertencimento a um grupo, daí a memória coletiva.

Assim no meio de tantas descobertas, as entrevistas foram concebidas na realização da pesquisa como uma troca necessária de diálogo entre dois sujeitos, pois uma pessoa não pode compreender a outra a menos que haja uma troca entre ambos, para que juntos estejam aptos para a troca e comunicação. Foi importante compreender o cuidado com o outro e sua história e também entendemos a dimensão necessária de não ser pertencente ao grupo gestor, pois assim, não se sentiram ameaçados e não esconderam informações importantes da gestão. Nesse contexto, Thompson defende que o entrevistador deve ter:

Há algumas qualidades essenciais que o entrevistador bem-sucedido deve possuir: interesse e respeito pelos outros como pessoas e flexibilidade nas reações em relação a eles; capacidade de demonstrar compreensão e simpatia pela opinião deles; e, acima de tudo, disposição para ficar calado e escutar. Quem não consegue parar de falar, nem resistir à tentação de discordar do informante ou de lhe impor suas próprias ideias, irá obter informações que, ou são inúteis, ou positivamente enganosas. Mas a maioria das pessoas consegue aprender a entrevistar bem (THOMPSON, 1988, p. 254).

Assim, a ética na pesquisa se deu primeiramente com a análise da pesquisa e do roteiro de entrevista pelo Comitê de Ética em Pesquisa (CEP) na Plataforma Brasil, o que foi um desafio devido à demora da aprovação e à quantidade de documentos solicitados. A ética também foi aplicada na transcrição das entrevistas, sendo que ao término da transcrição, foi enviado para cada um a entrevista transcrita e perguntei se desejavam realizar alguma alteração. Dos cinco entrevistados, três pediram alterações, desse modo, a solicitação dos mesmos foi atendida. Mendonça me enviou os tópicos que gostaria que fosse modificado; já Silva alterou o documento e me enviou o arquivo final modificado; e Torres me disse que iria fazer alterações e me enviar o arquivo, o que se tornou um grande desafio, pois a mesma demorou muito a dar retorno.

\section{Uberlândia nos anos de Abertura Política}

Para entender como Zaire Rezende foi eleito em 1982, foi importante rever o processo de crescimento expansão da cidade Uberlândia e quem foi esse político que se elegeu logo após a ditadura militar, tendo em vista que desde a sua primeira candidatura, estabeleceu-se um jogo político, entre a direita conservadora e os chamados esquerda democrática. Para entender como a política se processou na cidade de Uberlândia foi também necessário compreender quem eram os governantes que detinham do poder naquele período na cidade de Uberlândia, e como o governo Zaire Resende articula com a classe trabalhadora. 
Uberlândia, tinha 94 anos de emancipação política no ano de 1982, é uma cidade considerada importante, pois aloja um dos maiores atacadista do País, que é grupo Martins.

Nos estudos de Alem (1991) e Jesus (2008) eles mostram que mesmo que Uberlândia tenha sido, desde a sua fundação, uma cidade de pequeno porte, a maioria de seus governantes atuaram no sentido de fazer com que ela se tornasse moderna, trazendo avanço econômico, o que pode ser evidenciado no governo de Juscelino Kubitscheck. Apesar, desse avanço, ter ocorrido, fazendo com que a cidade fosse objeto de desejo de muitos moradores da região com promessas de vida melhor, não se pode deixar de notar que a sua vida cultural tinha sede somente no centro da cidade. Aqueles que vinham para Uberlândia com promessas de melhorar de vida e por razões financeiras iam morar na periferia, não tinham acesso à vida cultural da cidade, e muitas vezes não se sentindo parte da sociedade local, pois os trabalhadores não tinham acesso aos bens culturais construídos pela e para a elite.

Uberlândia, chamada de São Pedro de Uberabinha até 1929, precisava passar por reformas para atrair novos moradores e tornar-se uma cidade de desejo e de perspectiva de uma vida melhor. Para isso era preciso crescer no aspecto econômico, principalmente com a vinda de sua autonomia administrativa. Essa necessidade de crescimento se deu na disputa do poder das instituições que estavam sob o domínio da oligarquia rural.

Salta aos olhos o fato de que desde 1888 (período da emancipação política de Uberlândia) até 1982, todas as administrações que estiveram à frente do executivo municipal mantiveram características bastante semelhantes na forma de conceber a gestão pública. Governada por militares, ruralistas, farmacêuticos, advogados, jornalistas e empresários, independente da classe social da qual eles se originaram, a linha política seguida esteve sempre voltada para fortalecer e expandir o capital econômico e financeiro, como os setores do comércio e da indústria e a especulação imobiliária. Sendo assim, as alternâncias de poder se deram ao longo de quase cem anos, mais em torno do nome de pessoas ou de grupos familiares do que em torno de propostas ou projetos para a cidade como um todo (JESUS, 2002, p. 4).

Alem (1991) analisa e pontua bem o medo que a elite tinha de que para que a cidade se tornasse moderna com a vinda de imigrantes (trabalhadores livres) era preciso que o seu então espaço urbano e a sua administração fossem públicos. E eles temiam a perda de poder, pois essa ocorreria como consequência da mudança de privado para público, dessa forma não os reconheceram como públicos, pois não teriam o controle político, não podendo garantir os interesses da elite. Para Souza (2011), essa confusão de privado para público se manteve, assim utilizaram o clientelismo, usando favores e promessas para agradar quem chegava em Uberlândia, nada de um compromisso oficial de melhoria de vida para aquelas pessoas, já que os interesses pessoais e políticos da elite estavam em jogo com a mudança de privado para público.

A cidade de Uberlândia por algum tempo teve apenas a história da elite estampada nas revistas e jornais, sendo que a troca de favores e promessas pelo voto fizeram com que a memória e a história dessas pessoas fossem silenciadas, não tendo espaço e não permitindo com que se sentissem parte da sociedade local. Foi então, com a eleição de Zaire, que, pela primeira vez, pessoas que nunca tiveram espaço poderiam se sentir importantes ao ter reuniões com o prefeito, como também de finalmente se sentirem como parte da história de Uberlândia. Souza (2011) nos apresenta como sempre foram 
autoritários os que se mantinham na administração municipal, não tendo o povo espaço para que fizessem parte e opinassem na tomada de decisões.

O PMDB (Partido do Movimento Democrático Brasileiro) chegou ao poder justamente por ter dado a oportunidade para que os menos favorecidos (a população que morava mais afastada da cidade) pudessem ter suas expectativas ouvidas.

Diante tal contexto, fica nítido o motivo pelo qual Zaire Rezende elegeu-se, tendo em vista o momento pelo qual o país havia acabado de sair, a ditadura. O slogan "democracia participativa" foi uma ferramenta necessária utilizada pelo ex-prefeito Zaire Rezende para que a população tivesse uma identidade, ao ir nas casas das pessoas e ouvilas. O candidato a prefeito via quem eram aquelas pessoas que, na sua maioria, eram sujeitos que não tinham seus anseios atendidos. Assim, por ter havido esse contato direto com a população por meio de uma campanha denominada de "democracia participativa", o povo sentiu-se valorizado e importante, ao serem ouvidos.

Esta forma de relação, que reconhecia a existência e a fala dos moradores, acenava com o reconhecimento do Prefeito como um "amigo", mas um amigo que "podia mais". Este posicionamento, em uma sociedade onde as relações sociais se estabelecem produzindo/sustentando culturalmente uma relação clientelista e patrimonialista, possibilitava o reconhecimento e o acesso a alguém que, apesar de diferente, socialmente apresentava-se como igual. Esta condição é relevante e diferenciadora numa sociedade que se caracteriza pelo favorecimento (SANTOS; CARDOSO, 2007, p. 11).

De acordo com Santos e Cardoso (2007) e Alem (1991), o Brasil estava crescendo economicamente e houve o aumento significativo de edifícios, contudo, a população estava sendo deixada de lado e, consequentemente, marginalizada, assim tendo a sua identidade oculta e menosprezada por aqueles que sempre tinham suas vontades atendidas pela Administração Municipal. Como na ditadura militar isso já ocorria, era de extrema urgência então que a participação das pessoas se efetivasse, tendo em vista o progresso cultural da cidade e, para isso, era necessário um prefeito que os conhecessem e entendesse as dificuldades enfrentadas no seu cotidiano e, com isso, pudesse intervir para seu desenvolvimento.

\section{Do golpe militar ao processo de democratização: a democracia participativa em Uberlândia}

A repressão política e a exploração econômica foram fatores que influenciaram o aparecimento dos movimentos populares. Os discursos sobre democracia em um período que o Brasil vivia sob a ditadura militar deu um impulso maior para que eles propagassem e ganhassem força. A luta por seus direitos foi o que despertou ainda mais o desejo da população carente fazer parte desses. Embora essa população estivesse entusiasmada para fazer parte dessas organizações, sua carência não era motivo suficiente para organizar as lutas nesses movimentos, já que viviam de modo desorganizado politicamente.

Para Santos e Cardoso, 
Zaire Rezende identificou o autoritarismo dos governos militares como (o) produtor das mazelas sociais vividas no país. Apresentou a corrupção das ações públicas e o uso inadequado do dinheiro público como problemas decorrentes deste autoritarismo, que deveria ser enfrentado, pois a opinião pública, insatisfeita, movimentava-se pelo desejo de mudança, também em Uberlândia (2007, p. 7).

Pelo Brasil ter vivenciado um processo de autoritarismo característica de uma ditadura militar, período que antecedeu a primeira gestão intitulada de democrática na cidade de Uberlândia no governo Zaire Rezende e por também por que a ditadura privou o povo brasileiro de ter acesso aos bens culturais, a população uberlandense enxergou uma possibilidade de ser ouvido numa gestão chamada de democrática. A "democracia participativa" incitou que os bairros se organizassem para fazerem suas reivindicações e assim foram criadas as associações de moradores de bairros.

$\mathrm{Na}$ narrativa de Rezende (2015) ex-prefeito, ela narra sobre os princípios que regeram a sua proposta para a ação municipal de 1982 a 1988.

Proposta para a ação do governo municipal, Uberlândia, Minas Gerais, venceremos! E aqui nós, nós temos aqui uma introdução onde a gente fala várias observações! E depois os princípios para a ação do governo. Começa com isso, nós dizemos o seguinte, são 10 princípios. O PMDB tem princípios e ideias básicas que norteiam a ação do governo municipal, destacamos os seguintes: a ação do governo deverá estar sempre voltada para o ser humano, objeto e sujeito do desenvolvimento social, 2, o reconhecimento de que os problemas básicos do município derivam da má distribuição de renda (persiste até hoje, existe os ricos no centro da cidade e os pobres na periferia), do êxodo rural, do desemprego ou do subemprego e da má utilização dos recursos públicos, o que obriga grande parcela de nossa população a viver abaixo das condições mínimas de dignidade, segurança e esperança no futuro. Para nós constitui-se em prioridade a solução desses problemas, mesmo que a capacidade de ação do governo municipal seja limitada. O objetivo central do PMDB é erradicar a miséria e assegurar trabalho, dignidade e participação, participação ao povo brasileiro. Agora essa outra terceira aqui, eu acho que é fundamental, é o centro; o reconhecimento do direito do povo de ser construtor de seu próprio destino, (certo, da mesma forma como eu, você ou qualquer pessoa, tem o direito de construir a sua personalidade, a sua maneira de viver, a sua maneira de ser e constrói o seu, busca a sua realização afetiva, sua realização no trabalho, sua realização intelectual, enfim, o povo tem direito e ai continua) o reconhecimento do direito do povo ser construtor de seu próprio destino e que nos remete à defesa da democracia, através da mobilização popular, como condição necessária para exigir e encaminhar as reformas sociais e econômicas que se impõem, está vendo, perigoso! 4, absoluto respeito e defesa das liberdades democráticas, o direito de livre pensamento, associação e expressão. Quinto, o reconhecimento da independência dos poderes executivo, legislativo e judiciário como indispensável à manutenção das liberdades civis, ao cumprimento das leis e a fiscalização dos poderes públicos. 6 , ah esse aqui também é importantíssimo, o que não é comum, o entendimento de que a finalidade exclusiva dos poderes públicos é servir à comunidade, não se admitindo o uso do cargo público em benefício pessoal, não se admitindo o uso do cargo público em benefício pessoal, prefeito, vereadores, secretários ou funcionários do povo, 
municipais são empregados do povo, pagos por ele. Quem é o patrão, é o povo, é na cidade, é no estado, é no Brasil; quem é o patrão da Dilma é o povo, quem é o patrão do Pimentel é o povo, quem é o patrão do Gilmar é o povo, entende? Isso, o povo brasileiro necessita colocar isso dentro do cérebro, entende? Até o último neurônio, para poder ter consciência dos seus direitos, entende? O dono, o patrão, certo? É, 7, o governo do município deve estar voltado para todos os uberlandenses, todos, sem qualquer tipo de discriminação. Considerar-se-á, contudo, pela relativa escassez de recursos, as prioridades estabelecidas nos planos de governo. Plano de governo feito junto com a população, certo? 8 , a exigência de respeito ao patrimônio público, mantendo-se inclusive, as obras já conquistadas. 9, a aplicação, é outra coisa primordial, a aplicação dos recursos públicos deverá obedecer um planejamento elaborado com a participação efetiva da comunidade, é a participação, seja através da Câmara de Vereadores, seja através de outros órgãos ou mecanismos a serem criados e nós mandamos a criação das associações de moradores, associação de tudo quanto é coisa, de sindicatos, nós estimulamos isso ao máximo durante o governo. E 10, o defeso, a defesa da autonomia municipal (o município tem que ser autônomo) e de uma reforma tributária que a via, viabilize a articulação com os demais municípios da região para esse e outros fins, certo? Então esses são os princípios (ROMERO, 2015, pp. 215-216).

Em seus princípios de governo é perceptível identificar que suas ações seriam voltadas para a maioria da população e não mais para a elite. Enfatizou no princípio sete, e que a má distribuição de renda fez com que aqueles que mais necessitam estar perto do centro da cidade, onde o acesso a escola, ao teatro e a biblioteca é mais fácil, encontram-se na periferia, onde o acesso é sempre mais difícil. A participação do povo foi evidenciada, chamando a atenção ao seu princípio de número três, que mostra que é o povo pode construir seu próprio destino.

Diante de processo, posso afirmar que foi esse princípio que motivou Rezende a criar as associações de moradores de bairros, para que o povo se organizasse minimamente e para que as prioridades de cada bairro fossem sanadas, levando em consideração a distância em que se encontrava a periferia ao centro da cidade onde o acesso era mais fácil a escolas, bibliotecas e ao teatro. Já em seu princípio de número seis, no qual relata que seu entendimento dos poderes públicos é servir a comunidade, posso compreender que ele enfatiza que é o povo que governa, sendo assim, coloca-se à disposição dele. O princípio de número oito, fala sobre o respeito ao patrimônio público. Nesse caso especifico, podemos pontuar a Biblioteca Pública Municipal Juscelino Kubitschek de Oliveira, que antes de ser biblioteca havia sido uma rodoviária, nesse mesmo governo a secretaria de cultura cria o Carro-biblioteca que circulava nos bairros para levar a aqueles que não podiam pagar o ônibus até o centro, tivessem acesso aos livros.

Podemos inferir que Alvarenga (1988) relata que as práticas que levantavam a democracia, surgidas em eleição, somente com o intuito de vencer, normalmente desaparecem quando quem se candidata chega ao poder. Para Silva (2004, p. 52), nos momentos eleitorais sobressai o clientelismo, dissimulado ou não, ou seja, o voto de cabresto, o voto personalista, as promessas salvadoras, que só existem enquanto promessa de campanha política. Jesus (2008) afirma que os interesses do povo e de quem se elege diferem-se, no sentido de que quando a população organiza-se em forma de movimentos populares, pressupõe-se que o Estado não interfira. No entanto, no governo Zaire Rezende as associações de bairros foram criadas justamente para que o povo reivindicasse suas 
necessidades perante as dificuldades enfrentadas na sua realidade de vida. Podemos entender que mesmo que o movimento popular prefira a não intervenção do Estado, sendo então um movimento independente, vemos que no governo Zaire Rezende foi necessário a implementação da associação de moradores de bairros para que a participação tão enfatizada no seu slogan de "democracia participativa" se efetivasse.

Ferreira (2010) nas suas narrativas explicita que as pessoas que saíam da zona rural para a urbana encontraram na cidade um alto custo de vida, assim muitos foram morar na periferia da cidade, que por sua vez ficava longe do centro, sendo essa organizada em conjuntos habitacionais. A justificativa dada pelo governo para a construção dos conjuntos habitacionais longe do centro da cidade era diferente ao que parecia, o governo justificava a distância remetendo ao crescimento do município, seu desenvolvimento, progresso e organização pacífica, já os críticos viam os conjuntos habitacionais como especulação imobiliária, benefício para a elite.

Nesse sentido, compreendo que a localização das pessoas que mais precisavam ter acesso à leitura e à cultura se encontravam na periferia:

Uberlândia, inserida nas relações capitalistas de produção, possui uma divisão social do espaço caracterizada nos mesmos moldes das cidades capitalistas do Terceiro Mundo: as melhores áreas servidas de todo o equipamento coletivo, ocupadas pelas classes sociais de maior poder aquisitivo, restando às classes populares, segregadas social e espacialmente - a periferia urbana, carente de toda ordem dos bens de consumo coletivo (SOARES, 1988, p. 93).

Diante dos estudos realizados por Ferreira (2010), Soares (1988) e Jesus (2008) podemos afirmar que quanto mais longe a população carente estiver do centro da cidade menos acesso teriam a cultura e a leitura. De acordo com os interesses políticos de quem estava no poder, assim continuariam, sem ter esse acesso que, ao que parece, a elite queria que fosse exclusivamente dela. Isto porque era no centro de Uberlândia que a vida cultural da cidade se encontrava, especialmente por possuir, na época, escolas mais equipadas, bibliotecas e teatro, cinemas, fazendo com que a população carente que muitas vezes não tinham dinheiro para pagar o ônibus, não frequentassem esses espaços.

Para ganhar as eleições, Zaire destacou a importância da participação da população nas tomadas de decisões em seu governo, por exemplo, os bairros da cidade de Uberlândia foram edificados através da relação de seus moradores com o dos outros bairros. As relações normalmente não eram muito amigáveis no sentido de dar rótulos para aqueles bairros que possuíam diferentes realidades de vida que eram exacerbadas, acreditava-se que nos bairros periféricos moravam pessoas ligadas ao tráfico de drogas, pessoas violentas, pobres, entre outros, manifestando nesses rótulos a luta pelo poder político. Assim, em suas propostas, Zaire Rezende se colocou a disposição para saber por essas pessoas que estavam marginalizadas pela sociedade, suas necessidades. Ele baseou-se nas democracias tanto participativa, como a representativa.

Para Silva, esclarece que: 
Olha, eu acho que esse primeiro, embora hoje eu não concorde mais com esse nome de democracia participativa, eu acho que democracia é democracia! Não tem que, porque isso aí, democracia participativa é pra se contrapor à democracia representativa, é um rótulo que precisava existir naquela época, pra mostrar assim, que ali não é só porque o prefeito foi eleito e os vereadores foram eleitos e eles são representantes do povo que é democracia representativa, mas assim essa democracia, além de representativa ela é participativa e engoliu o representativo pra ficar participativo e mostrar a importância da participação das pessoas nesse governo. Eu acredito que sim, nós estamos falando desse período que é o primeiro mandato dele, eu acredito que sim nesse primeiro mandato, ficou uma coisa mais pura, é por que, porque tem vários elementos aí que eu acho que são importantes. O primeiro deles é o seguinte, o país estava saindo de uma ditadura militar, então todos os esforços que pudessem ser feitos para que a gente saísse daquela situação eram esforços importantes. Então por exemplo é não era difícil encontrar partidos que aparentemente são de oposição, seriam de oposição, se juntando pra partidos não, porque existiam poucos partidos, mas pessoas que eram aparentemente de oposição, mas que se juntavam em prol de um objetivo, que era o objetivo, uma certa libertação daquele sistema ditatorial que a gente vivia, é nesse sentido eu acho que é uma avaliação positiva e é, por que, porque o momento era esse então, lógico que havia oposição, aquelas coisas, havia um ranço grande de uma cidade que é uma cidade conservadora e autoritária que Uberlândia ainda é um pouco muito isso, tradicionalista, autoritária, pa pa pa essa coisa meio provinciana, não sei se você é daqui, eu sou daqui, então eu posso falar isso tudo porque eu sou filha de Uberlândia. É foi um governo que foi contra tudo isso que queria dar voz ao outro grupo de pessoas que tinham tido pouquíssimas vezes de se expressar aqui dentro da cidade, que era uma cultura elitista, a cultura para os governos anteriores, a ideia anterior de cultura é aquela que eu te falei, que a cultura de arte, de erudição e acadêmica, que não é. Não tá errado de jeito nenhum, mas só isso era cultura entendeu? E nunca houve ou tinha havido disponibilidade da administração, das administrações públicas de tentar pegar, mostrar ou sei lá, fazer com que essa cultura, que houvesse uma aproximação entre as formas diferentes de cultura, então nesse sentido eu acho que é positivo, que foi positivo (ROMERO, 2015, pp. 196-197).

De acordo com Silva (2015) podemos afirmar que a denominação democracia participativa foi necessária para diferenciar do que vinha sendo feito pelas gestões anteriores, e ela foi pensada para aqueles que não tinham espaço para se expressar dentro da sociedade de Uberlândia. Com o fim da ditadura militar, essas pessoas que vinham para a cidade com a intenção de ter uma vida melhor e iam morar na periferia acabavam não tendo esse espaço. A democracia representativa ocorreu, com a eleição de Zaire Rezende, o que aconteceu foi que mesmo o povo tendo utilizado o voto, não ficaria apenas por isso, segundo as narrativas elas foram ouvidas e tiveram espaço no governo.

O Conselho Municipal de Entidades Comunitárias (CMEC) foi criado justamente para fazer o intercâmbio entre os movimentos populares, as associações de moradores e o poder público municipal. Percebe-se que a partir daí as portas foram abertas para que a população pudesse reivindicar seus direitos, especialmente aqueles ligados à educação e ao incentivo da leitura, já que foi no governo de Zaire Rezende que a Biblioteca Pública Municipal "Juscelino Kubitschek de Oliveira” em Uberlândia, foi reinaugurada. 


\section{A democracia participativa na política de Uberlândia}

Em uma tentativa de propor uma organização nos bairros periféricos, o PMDB interagiu com o movimento nacional de redemocratização do país para garantir as eleições de 1982. Entre diversos debates ocorridos com o intuito de saná-los, é que deu origem a proposta de Democracia Participativa.

De acordo com a Ata de número 119 da sessão em 18 de abril de 1983 define democracia participativa:

A democracia participativa possui vários fundamentos que a tornou viável e necessários.

- Um fundamento sociológico, dados "pelas estruturas societárias, complexas e ampliação das relações sociais, o que significa fundamentalmente maior participação na vida coletiva.

- Um fundamento histórico, dado pela consciência do homem contemporâneo que não pretende continuar expectador da sociedade, mas deseja ser um agente dela;

- Um fundamento dado por uma filosofia da pessoa humana já que é de natureza humana. Aperfeiçoa sua atividade produtiva graças à possibilidade de atuar como responsabilidade pessoal e aperfeiçoa o próprio ser, através da participação consciente e responsável das pessoas e grupos que integram a comunidade.

Há também um fundamento político o artigo 21 da Declaração Universal dos Direitos do Homem, no determinar que "a vontade do povo será a autoridade do governo".

A democracia participativa possui, ainda um fundamento psicológico, na medida em que o sentimento de participação é um fator poderoso para propulsionar a atividade humana, a participação organizada é um fator poderoso para a educação e o desenvolvimento.

A democracia participativa possui, enfim, um fundamento de ordem técnica, qual seja, a viabilidade, adequação e harmonia de um planejamento possíveis somente quando os interessados participaram da discussão do plano. Sob esse ângulo, é um meio privilegiado para combater o compromisso e a manifestação que bloqueiam as democracias contemporâneas.

São instrumentos da democracia participativa no plano local, as comunidades da vizinhança; no plano do trabalho, os sindicados e associações de empregados e empregadores; no plano da juventude e da educação, os movimentos de jovens e os órgãos colegiados nas escolas; no plano político, os partidos democraticamente organizados, com direito assegurado.

As teses de participar na elaboração dos programas e na escolha dos candidatos. Assim, nesse despeitar da sociedade civil, trabalhadores pequenos e médios empresários, agricultores, moradores de bairros, artistas, etc, deixam de lado a passividade e passar a atuar, de forma consciente e organizado na solução de seus problemas. E este foi a opção de Uberlândia ao eleger para Prefeito Dr. Zaire Rezende. E a construção da democracia participativa não será feita por uma pessoa ou grupo de pessoas (é uma tarefa de todos nós). (UBERLÂNDIA, Fundo: Câmara Municipal; série: atas; subsérie: atas da Câmara Municipal; data: 01/1983 À 12/1983; No: 119. Ata da sessão em 18 de abril de 1983) 
Conforme o descrito acima, podemos inferir que o título de democracia participativa era necessário devido ser o governo de Zaire Rezende a primeira gestão democrática após o processo de reabertura política. Na versão da ata, inferimos que realmente esse título de democracia participativa era baseada na inserção daqueles que nunca tiveram espaço nas administrações municipais anteriores, de 1983 a 1988 tivessem e que de fato essa participação pode ser desenvolvida.

Nesse período, procurava-se que o processo democrático entrasse em vigor. $\mathrm{O}$ partido que mais se aliava às ideias de democracia e de descentralização administrativa era o PMDB, que também acreditava que a população pudesse se organizar para defender seus direitos e necessidades. A população periférica da cidade de Uberlândia passou a se organizar em Associações de Moradores (AM) a partir de 1978. Ao estarem organizados por associações, o representante de cada AM podia ter participação ativa em suas reivindicações no governo Zaire Rezende.

A Administração Municipal da cidade via na participação dos representantes das AM não como uma democracia participativa, mas como uma alternativa para ganhar votos ao atender as reivindicações da população.

Foi afirmado por um político da Administração na fase final da campanha eleitoral que lhe deu a vitória que se ganhassem as eleições a execução do programa lhe garantiria vitórias sucessivas. Ao invés das obras faraônicas este novo grupo político das classes dominantes optou pelas pequenas e múltiplas realizações no campo dos serviços urbanos de consumo coletivo que atingem as classes populares no seu cotidiano e podem consolidar o apoio político necessário nas eleições. Uma outra estratégia que despontou, ainda que discretamente, foi o emprego na prefeitura para algumas lideranças populares, ou cargos remunerados em empreendimentos de caráter social, no próprio bairro (ALVARENGA, 1991, p. 107).

Embora a crítica de Alvarenga (1991) venha contradizer a participação no governo Zaire, podemos ver pela fala das entrevistadas a importância que essa participação teve entre 1983 a 1988, como também perceber que de fato ouve esse envolvimento da população, apesar de não ter sido possível atender a todas as demandas.

É, assim, a gente participava, a secretária, eu lembro da gente estar sempre fazendo pesquisa, fazendo levantamento nos bairros, pra saber que é que a população queria, então isso existia mesmo, a gente ia e tudo, mas dentro do que era possível, era realizado! Agora 100\% não conseguia, porque sempre você vai esbarrar na questão financeira, então a Secretaria naquela época tinha uma verba ainda bem menorzinha do que tem hoje. E, mais a gente fazia, a secretária tinha todo o empenho, o prefeito tinha todo o empenho, a gente ia nos distritos em reunião das associações, então assim, eu lembro disso, e a gente tentava atender sim, o anseio, então assim, buscava sim atender essas, satisfazer a comunidade para ser democrático mesmo, era esse o nosso lema mesmo. (ROMERO, 2015, p. 188).

Ainda contestando sobre a participação no governo Zaire Rezende, podemos ver que de acordo com a Ata de número 119 da segunda sessão da sexta reunião ordinária de 1983 realizada em 17 de agosto de 1983 - quarta-feira: 
Adriano Bailoni Júnior usando o tempo da liderança disse de sua alegria em ter leitores cultos, embora contestando-o com mentiras, despreparados e sem intimidade com administração e o poder público, neófitos em na vida pública e marginalizados do poder à vida toda, agora vem dizer mentirosamente aquilo que entendem, porque a tribuna é livre e cada um fala o que quer. Confirmou que escreveu artigo dizendo da falta de credibilidade do governo municipal, e também dos vereadores do PMDB radical, por que eles mentiram na campanha não está escrito em lugar nenhum; o que mentiram e agora fazem é a negação de tudo que prometeram. Não conhecem o direito, só sabes mentir, à partir do prefeito ZAIRE REZENDE, que é inocente, por suas declarações constrangedoras ao dizer que o povo aprovou sua proposta. $O$ povo não aprovou nada, não sabia de nada, acreditou nas mentiras como ônibus mais barato, asfalto de graça, prestações do $\mathrm{BNH}$ de graça, sem correção monetária, o preço baixo da água, e isto é vergonhoso. Vereadores como a líder do Sr. Prefeito vem aqui envergonhar mais a situação de hoje. Não há ninguém nesta cidade que tenha a ombridade de afirmar agora que votou em Zaire Rezende, todos envergonhados e a cidade entristecida porque caiu num conto do vigário. Não imaginava eleger um homem e sua equipe que tem demonstrado falta de preparo político e administrativo, não entendendo de nada. No momento em que alegam dificuldades financeiras mandam uma proposta criando mais sete secretarias aumentando no curso de seis anos mais de um bilhão de custo. O Prefeito só assina papéis, não tem senso administrativo, fez promessas e não cumpre. (UBERLÂNDIA, Fundo: Câmara Municipal; Série: Atas; Subsérie: Atas da Câmara Municipal; Data: 01/1983 à 12/1983; No: 119)

A ata de número 119 da Câmara do dia 17 de agosto de 1983, reafirma a fala de Carvalho (2015) é que apesar do governo ter em seu discurso o atendimento a população pela democracia participativa, o orçamento muitas vezes não conseguia sanar todos os pedidos. No entanto, foi feito o possível para edificar as propostas do povo. Adriano Bailoni Júnior ${ }^{3}$ nega o fato do povo ter aprovado as propostas do governo Zaire, o que aconteceu foram as reuniões feitas, como pode ser visto na sua proposta de ação para o governo. Ele relata que esses encontros com a população o ajudaram a construir sua proposta de ação para o governo, deixando claro que a participação se deu de fato. Conforme Rezende:

Quando chegávamos na segunda-feira, nós pegávamos todo aquele material que foi relatado, líamos, fazíamos um resumo daquelas reuniões todas, as ideias que saíram, entende? E colocava no papel e colocava dentro daquelas ideias, as propostas nossas, o pensamento do PMDB e o nosso pensamento também e fomos arquivando e na terça-feira a gente começava a discutir qual seria a próxima, a próxima reunião, qual seria o tema da próxima reunião. Então escrevia alguma coisa e discutíamos entre nós, estabelecíamos onde seriam as reuniões e como é que seria feito a coordenação e tudo o mais, o planejamento e quando terminávamos as reuniões nos bairros, a gente sempre perguntava, tem alguém que gostaria de oferecer a sua casa para fazer a reunião? Apareciam mais 1, 2, 3, pessoas, famílias que queriam que fizessem reunião, então sempre tinha lugar para fazer a reunião, ou a reunião no bairro ou no outro bairro. Mas, foi assim que nós fizemos, nós não forçamos reunião nenhuma, o povo que escolhia, queria e escolhia o local e a gente, depois que a gente lia, a gente ouvia a opinião de um por um. E 
procurava saber, a senhora quer falar, você quer falar? Se a pessoa ficava assim meio sem graça, a gente passava a roda e quando a gente voltava, a gente falava, quer falar agora? (ROMERO, 2015, p.213).

Percebo que há uma contradição entre a afirmação de Adriano Bailoni Júnior, que disse que o povo não aprovou a proposta de Zaire e na fala de Rezende (2015). Com essas reuniões, o povo o ajudou a construir a sua proposta de ação no governo municipal e continuou ouvindo a população já com a criação de associações de moradores. Como confirma Santos:

Esse documento continha, em sua grande parte, as demandas reclamadas pelos eleitores expropriados e explorados da cidade, os quais tinham suas necessidades contempladas na redação impressa de um documento oficial de campanha. Era um compromisso que, em si mesmo, consolidava o reconhecimento da voz dos "invisíveis", dos excluídos; enfim, dos insatisfeitos com suas condições de vida e do tratamento que recebiam em seus momentos de insatisfação e/ou resistência (SANTOS, 2006, p. 8).

Alvarenga (1991) critica a participação do povo no governo Zaire Rezende, afirmando que as institucionalizações das AM não deixaram que novas formas de relação pudessem ser vivenciadas, além de que quando se reuniam com a administração municipal era apenas para formarem uma lista com a ordem de prioridades de suas necessidades reivindicadas. Alvarenga afirma também que nas reuniões, os membros da Prefeitura faziam questão de apresentar os dados por meio de muitas planilhas e números, de forma que se dificultasse o entendimento dos representantes, tanto das AM como das outras organizações populares. Assim, houve a criação do Conselho Municipal de Entidades Comunitárias (CMEC), que exerceu a função de mediação entre as AM, outras organizações populares e o Poder Municipal. Mesmo com a desconfiança, era de interesse da Prefeitura ter um elemento que pudesse atuar como um "amortecedor" para conter as medidas impopulares, através da mediação.

\section{A Biblioteca Pública Municipal Juscelino Kubitschek de Oliveira no governo de Zaire Rezende}

A Biblioteca Pública Municipal Juscelino Kubitschek de Oliveira foi criada no dia 24 de outubro de 1940, sendo a primeira biblioteca da cidade. A sua criação ocorreu sob o decreto Lei $n^{\circ} 81$, na gestão de Vasco Gifone.

No governo Zaire Rezende (1983-1988) a população ganhou espaço para reivindicar seus direitos, quem representava a população eram as associações de moradores dos bairros, sendo que de acordo com os documentos pesquisados tanto no Arquivo Público como na biblioteca, a interação entre a comunidade e a Biblioteca era intensa e constante. Também é interessante destacar que a Biblioteca Pública Municipal Juscelino Kubitschek de Oliveira está ligada à Secretaria de Cultura e não à de Educação.

Para Silva: 
Então, a educação assim, enquanto a gente, no começo era educação e cultura, é aquilo que eu te falei, achava assim que é uma dificuldade muito grande em qualquer área pode ser Ministério da Cultura, pode ser Secretaria de Estado, pode ser Secretaria Municipal, quando a Secretaria de Educação e Cultura as coisas são muito travadas, quando separa as coisas ficam muito distantes, não deveria nunca ser assim. Mas quando é, em se tratando de Secretaria de Cultura mesmo é, eu me lembro que a gente tentava fazer alguns projetos integrados, algumas coisas assim, fazíamos coisas em escola principalmente a Beatriz que trabalhava com a área de extensão cultural e a literatura infantil, a gente tentava fazer algumas coisas relacionadas com as escolas dos bairros, mas assim acho que sem muita intermediação com a Secretaria de Cultura, mas direto com escolas ou o carro-biblioteca agindo ali de acordo ou ficando perto de escola, a gente sempre pensava nisso, então era um, é acho que esse tipo de relação que a gente estabeleceu, de participação, menos formal. Não era uma coisa conversada e tudo, não que eu me lembre tanto assim, era mais ações mesmo que a gente buscava aproximação (ROMERO, 2015, p.194-195).

O dia de 28 de agosto de 1976 é que marcou esse novo local, foi nesse dia que todo o acervo e todos os móveis foram levados para a nova moradia da Biblioteca. Nesse mesmo mês, no dia do aniversário da cidade, em 31 de agosto, é que a biblioteca foi entregue para a comunidade, recebendo o nome de Biblioteca Pública Municipal Juscelino Kubitschek de Oliveira, em homenagem ao ex-presidente que morreu em 22 de agosto de 1976.

Em 1980 a Secretaria de Cultura foi criada, tendo como secretária a professora Iolanda de Lima Freitas. Com a criação da Secretaria de Cultura, a biblioteca passou a ficar sob responsabilidade dessa Secretaria, com a coordenação da bibliotecária Terezinha Elizabeth da Silva, que assumiu esse cargo na administração do prefeito Zaire Rezende. Reformas na biblioteca foram necessárias para que a população pudesse ter acesso aos livros e, consequentemente, a leitura, como também projetos foram implantados.

A reportagem do Jornal Primeira Hora de 23 de dezembro de 1983 apontou que a vitória de Iolanda foi uma vitória feminina, já que um grupo de mulheres reivindicavam a representação deste gênero no governo de Zaire. Ela concorreu com Brito, que teve protestos a seu favor para dar posse ao cargo. Apesar de já estar trabalhando, Iolanda aceitou com agrado o convite. Ela ressaltou a importância da conservação do patrimônio histórico e das manifestações culturais com a colaboração dos grupos culturais da cidade, com o objetivo de realizar planos que fomentariam as ações da Secretaria de Cultura, apesar de ter sido rotulada de elitista.

Nas entrevistas concedidas percebemos que Iolanda de Lima Freitas foi convidada para atuar como Secretária de Cultura do município. Tanto Carvalho (2015) como Silva (2015) haviam procurado informações para começar a trabalhar. Já Mendonça (2015) foi a ganhadora de um concurso que a biblioteca pública desenvolveu, "Descubra o contador de histórias do seu bairro" e então foi convidada a trabalhar na biblioteca; Torres (2015), por ter sido aluna de Iolanda, foi indicada para o cargo.

Em 1987 é a vez do Carro-Biblioteca ganhar seu espaço, com a coordenação de Carvalho (2015). O objetivo era fazer com que a biblioteca, ao ter a descentralização de seus serviços, pudesse estar mais perto da população que vivia nos bairros mais afastados, ao proporcionar o contato com os serviços bibliotecários e de extensão cultural para que os desfrutassem. O ano de 1988 foi bastante importante para a biblioteca, pois era o ano do centenário da cidade. Para comemorar foi criado o Projeto "Descubra o contador de 
história do seu bairro", tendo ocorrido o lançamento no Bairro Liberdade, pelo Projeto Circo e a Caixa Estante. Maria Inês Mendonça foi descoberta como sendo a contadora de história e, assim, mais tarde veio a trabalhar na Sala Infanto-Juvenil em escolas estaduais, municipais, creches e unidades de menores e os bairros atendidos pelo "Projeto Circo" e a Vovó Caximbó.

\section{A preocupação com a leitura e a cultura no governo Zaire Rezende}

No período do governo Zaire (1983-1988) houve uma preocupação com a educação e a cultura. Tanto que em seu governo foram implantados inúmeros projetos pela Secretaria Municipal de Cultura que visavam colocar em prática e atrair adeptos para a leitura e a cultura. Para relatar os projetos desenvolvidos pela Secretaria de Cultura de Uberlândia no governo de Zaire foi feita uma pesquisa documental, tanto no arquivo público municipal como na Biblioteca Pública Municipal Juscelino Kubitschek de Oliveira. Nesses espaços foram encontradas atas e cópias dos projetos da Secretaria que visavam, através da reivindicação da população dos bairros periféricos, a disseminação da leitura e a cultura.

Como Rezende utilizou o orçamento para a implantação dos projetos.

Naquele tempo não era um momento muito rico para as prefeituras; mas eu acho que hoje está pior para as prefeituras! Sempre tínhamos algum recurso, então nós podemos fazer, tivemos a possibilidade de incentivar toda essa área que permitisse mais leitura, mais acesso à leitura. (ROMERO, 2015, p.214).

Rezende afirmou que não era um momento rico para as prefeituras. Mesmo com o orçamento pequeno, percebemos a vontade do grupo para que todos os projetos acontecessem. Já Torres na sua narrativa relata que ela não lembrava de nenhuma reivindicação de leitura feita pela população:

Que eu me lembre não. A AULA, esse projeto, ele é reivindicação da AULA, que era uma Academia Uberlandense de Letras e Artes. Esse projeto nasceu da reivindicação de vários segmentos, inclusive da Academia Uberlandense de Letras e Artes. E de uma comunidade que escolheu a literatura como forma de expressão artística que usa como instrumento de trabalho a palavra. Tá vendo, nós criamos em 85 que era a edição anual de obras inéditas, literária e científica de escritores uberlandenses. Então isso é uma demanda da sociedade. (ROMERO, 2016, p.230).

Já Carvalho narra que houve reivindicações de leitura dentro dos projetos desenvolvidos na biblioteca.

Eles pediam sim para melhorar o acervo do carro-biblioteca e a gente sempre dentro do possível, a secretária comprava mais livros, para poder atender, não só esse projeto do carro-biblioteca, como atender a demanda que era muito grande na biblioteca, então eu lembro de ter fila para entrar, principalmente na parte da tarde, sempre o movimento da tarde foi maior. Tinha fila para entrar, ficavam esperando, às vezes ficava tudo cheio. Então ficavam filas lá fora aguardando para poder entrar. (ROMERO, 2015, p.188). 
Embora Torres (2015) não se lembre da reivindicação da população, podemos perceber que de fato ela existiu como denota as falas de Rezende (2015) e Carvalho (2015) em co-relação com as demandas da Academia Uberlandense de Letras e Artes (AULA).

Rezende relembra a preocupação que o governo tinha com a leitura.

Nós primeiro, nós ficamos preocupados com a possibilidade de ler do povo, para poder ler mais, nós então fizemos uma reforma na secretaria da biblioteca, contratamos uma profissional que estivesse realmente habilitação como bibliotecária, então habilitação universitária como bibliotecária. Nós criamos também um espaço da Secretaria de Cultura, um espaço próprio que era um prédio antigo que tinha aqui, nós compramos o prédio, fizemos uma reforma e fizemos a inauguração, e transformou também no local de trabalho da Secretaria de Cultura, certo? E então criamos um museu, um museu para prefeitura, museu, depende de outra área, o museu do índio e criamos uma coisa muito simples, mas muito importante que foi uma biblioteca volante. Naquele tempo nós compramos uma biblioteca kombi, uma kombi, uma perua kombi e transformamos numa biblioteca e nós saímos pelos bairros, parávamos lá e ofereciam livros para as pessoas poderem tomar emprestado para poder ler e a gente fazia, corria os bairros o tempo todo, alguns dias em um, outros dias no outro, marcando o dia de volta e quando nós então pegávamos o livro que já tinham sido lidos pela população, ficamos assim entusiasmados porque vimos que a população era sedenta por leitura (REZENDE, 2015).

O narrador insiste em relembrar a inúmeras tentativas que seu governo teve para que os moradores dos bairros pudessem ter acesso aos bens culturais, ele conta sobre a experiência de um leitor que teve acesso a biblioteca itinerante.

Nós tivemos alguns exemplos assim, muito bons, então foi uma coisa extraordinária. Uma empresa dialogando com as pessoas funcionárias e um deles que estava todo sujo e sentado no chão, assistindo o encontro nosso, ele disse que ele passou a ler livros graças à biblioteca volante, e teve uma outra senhora que eu fui informado que ela há cada 15 dias pegava 2, 3 livros e eu fiquei impressionado com aquela quantidade e fomos saber dela como que era, qual era a dinâmica que ela tinha. Ela tinha 2 filhos naquela época e ela se reunia com eles toda noite e lia os livros junto com eles (ROMERO, 2016, pp. 210-211).

Podemos identificar pela narrativa de Rezende (2015) que a preocupação pela leitura de fato existia, já que reformas foram feitas tanto pela separação da Secretaria de Educação e Cultura, como na biblioteca. Outro fato importante destacado pelo ex-prefeito é referente a biblioteca volante, no caso o carro-biblioteca.

Rezende (2015) narra um importante momento histórico que foi a separação das secretarias de educação e cultura. 


\begin{abstract}
As pessoas iam se animando, todas acabavam dando suas opiniões, as suas ideias e com isso, foi por isso que nós nessas reuniões, nós vimos que seria dar uma atenção muito grande à cultura, então percebemos que era necessário separar a educação que é uma área muito vasta, muito rica da cultura. Então colocamos lá, vamos fazer uma Secretaria de Cultura e aí discutindo com as pessoas também, vimos uma preocupação muito grande com o meio ambiente, poluição, desmatamentos, poluição de rio, poluição sonora, poluição aérea e até que nós chegamos a conclusão, é importante que tenha uma secretaria de meio ambiente, colocamos lá e não tinha. Não tinha cultura, não tinha meio ambiente e assim também a trabalho, porque a gente tinha que dar uma atenção aos trabalhadores, entende? (ROMERO, 2016, pp. 213-214).
\end{abstract}

Referente à narrativa de Rezende podemos compreender que a separação das secretarias de educação e cultura foi importante para que a cultura tivesse um espaço maior. A política cultural foi efetivada com a publicação do folheto da política cultural da Secretaria Municipal de Cultura de 1987. A reforma da biblioteca foi outro acontecimento importante, com a contratação de uma pessoa especializada em bibliotecas.

Para Feijó: “A cultura é um elemento da política. Há quem veja a política como um momento da cultura. De qualquer forma, desde que existe política, também existe elaboração cultural e uma ação comum em torno dela" (1985, p.10).

Para a Secretária Municipal de Cultura, no primeiro mandato de Zaire Rezende:

(...) entende Cultura no seu sentido mais amplo, como um processo que permeia toda ação humana, dando-lhe significado, estimando não apenas os valores do passado, mas também valorizando o seu aspecto de agente transformador da sociedade. Quem define o que é Cultura, enquanto valor social, é o povo. Cabe a nós administrar os recursos, canalizando ações no sentido de dinamizar ao máximo as atividades culturais do município (PREFEITURA MUNICIPAL DE UBERLÂNDIA, Secretaria Municipal de Cultura, Prefeito, Dr. Zaire Rezende, Secretária Municipal de Cultura, Pro. Iolanda de Lima Freitas 1983-1988).

A Biblioteca Pública Municipal Juscelino Kubitschek de Oliveira estava vinculada à Divisão de Cultura da Secretaria Municipal de Cultura. Essa Secretaria foi criada com a Lei no 3995 de 09 de setembro de 1983, no governo Zaire Rezende, tendo em vista que foi essa mesma lei que organizou a reforma administrativa de Uberlândia. Seu funcionamento ocorreu a partiu de 01 de fevereiro de 1984, juntamente com a posse da Secretária da Cultura, Iolanda de Lima Freitas. Antes da criação dessa Secretaria, todas as atividades que priorizavam a cultura estavam subordinadas à Secretaria Municipal de Educação e Cultura. A Secretaria estava dividida em departamentos, que eram: a Divisão do Patrimônio Histórico, a Divisão de cultura e Divisão de Bibliotecas. A Divisão de Cultura propiciava cursos para o aperfeiçoamento das atividades relacionadas à cultura. Com um trabalho conjunto com suas três divisões (Divisão de Cultura, de Patrimônio Histórico e de Bibliotecas), promovia todo ano o "Encontro de Política Cultural", durante três dias onde era promovido o debate da política e da questão cultural no país. O que a Secretaria Municipal de Cultura teve como objetivo, além de organizar e supervisionar as atividades em que era envolvida era garantir que a comunidade no geral soubesse das informações, eventos culturais e que participasse das atividades por ela desenvolvidas. Ao ter início das atividades da Secretaria Municipal de Cultura, a principal preocupação era conhecer a realidade em que Uberlândia se encontrava. 
Para incentivar a leitura nos distritos próximos a Uberlândia foi decidido implantar também Bibliotecas Comunitárias nos distritos de Cruzeiro dos Peixotos, Martinésia e Tapuirama, com opções de leitura sugeridas pelos alunos e membros da comunidade, para dar maior embasamento no processo de aprendizagem, sendo uma conexão entre a população e a escola.

Como já falamos anteriormente um dos projetos importantes foi a implantação do carro-biblioteca, que obteve as instruções necessárias para a sua implantação do Serviço Público Federal Ministério da Educação e Cultura e do Instituto Nacional do Livro. O estado direcionava quais seriam os objetivos que norteariam a ação cultural nas cidades. Os princípios básicos que deveriam priorizar eram facilitar o acesso da população, para que tivessem maior contato com a cultura, e tentar integrar a educação às suas atividades, colocando os cidadãos, assim, dentro do meio social em que vivem, como também colocando-os no papel de formadores de cultura, e chamando a atenção para a preservação do patrimônio histórico da cidade.

Silva conta como funcionava o carro-biblioteca (projeto de extensão) e que seu principal público era o infantil.

a gente tinha os dois projetos de extensão, as bibliotecas, o carrobiblioteca e as caixas estantes, porque eram o público dos bairros mais distantes mesmo que não tinham acesso a livros e leituras, assim que tinham, às vezes as escolas muito precárias em termos de recursos e então iam assim, o público, embora o público assim de modo geral fosse qualquer morador dos bairros, a gente percebia que era o público mais presente naquelas idas do carro e da caixa estante eram, era o público infantil, entendeu? Quer dizer que era uma boa, tinha também adultos e adolescentes, jovens e tal, mas era o público infantil que eram, que é legal, porque é por ali que tem que começar mesmo. No caso dos trabalhos da biblioteca infantil, o público infantil sem dúvida, mas agregando também as mães, mas aí já era um público não é do centro da cidade, mas assim dessa, do que tá aqui, do que é mais fácil, o acesso mais fácil, não vinha a pessoa lá do Alvorada, por exemplo, para participar de alguma coisa aqui, estou falando Alvorada porque o Alvorada era um bairro que o carro ia, não sei se vai e as pessoas que estudavam é que eram frequentadoras da biblioteca, participavam dessa outra política que era a utilização do próprio espaço da biblioteca com exposições, com filmes, com debates com pessoas que vinham, especialistas, filósofos e tal e aí é, quer dizer, era uma tentativa de abranger minimamente um pouco, representando um pouco assim da cidade. Agora acho que o público mais atingido mesmo e que mais interesse demonstrava era o público infantil, com certeza (ROMERO, 2016, pp. 192-193).

No ano de 1988 ainda houve o projeto "Descubra o contador de histórias do seu bairro", lançado no bairro Liberdade, pelo projeto Circo e a Caixa Estante. A grande ganhadora do concurso foi Maria Inês Mendonça, contadora de histórias que virou voluntária da biblioteca após ganhar o concurso. Maria Inês era gratificada com a parceria que Denise Carvalho havia feito com algumas livrarias. Mais tarde ela viria a trabalhar na Sala Infanto-juvenil em escolas estaduais, municipais, creches, unidades de menores e os bairros atendidos pelo Projeto Circo e a Vovó Caximbó. O Projeto Circo (1988) vinha com a proposta de viabilizar um espaço democrático, onde a comunidade poderia encontrar as resoluções para os seus problemas, sejam eles, o aperfeiçoamento artístico ou até mesmo 
os conflitos diários do bairro onde vivem. Caberia à comunidade decidir como as atividades iriam acontecer, já que haveria a interação da comunidade com a Secretaria Municipal de Cultura, juntamente com as associações de bairros na tentativa de haver trocas de experiências no incentivo a cultura local que era precária na época.

Rezende afirma na sua narrativa que:

Então essa oportunidade, esse estímulo, produziu resultados, nós vimos que existe sempre no meio da população os artistas de várias áreas, é o pintor entende? $\mathrm{O}$ ator, o músico, é o poeta, com vários tipos de poesia que iam lá e se apresentavam no circo. Sempre um espaço sendo colocado a disposição do povo, uma pessoa administrando sempre com alguém da Secretaria de Cultura junto para poder facilitar, para ajudar. Então, tudo isso acabou influenciando na cultura, influenciando também nessa possibilidade de leituras (ROMERO, 2016, p. 211).

Rezende apresenta a importância que o Circo itinerante teve perante as várias manifestações culturais que foram influenciadas pelo projeto, dentre elas a leitura.

Na narrativa de Carvalho:

Tinha o projeto da secretaria que era o circo itinerante, dentro do circo itinerante a gente colocou a caixa estante que era também uma pequena caixa com um acervo pequenininho de uns 200 livros, que a gente ia, é, eu não me lembro agora se 2 ou 3 vezes na semana para emprestar aonde o circo estava fixado. Ele ficava 6 meses rodando pela cidade, e, então tinha esse projeto dentro dessa caixa estante, a gente lançou um outro projeto que chamava "Descubra o contador de histórias do seu bairro", o primeiro lugar que a gente lançou esse concurso foi lá no beco de Santa Rosa e Liberdade e aí a gente descobriu a vovó Caximbó, que é a Maria Inês Mendonça, e o projeto de ônibus também, a gente convidou todas as associações que a gente tinha conhecimento e as que compareceram dentro daquelas é que foram feitos um sorteio, porque era uma kombi que ia atender 20 bairros, então dentro dos que apareceram, a gente fez um sorteio pra selecionar esses 20 e aí fechou esses 20 bairros e a gente começou com o trabalho com o do carro-biblioteca, que era uma kombi que comportava 900 livros, então era uma coisa bem pequenininha que hoje já tá um ônibus (ROMERO, 2016, p. 186).

Podemos constatar a importância que o projeto Circo itinerante teve na cidade de Uberlândia, levando em consideração a importância dada à leitura, tanto pela Biblioteca Pública Municipal quanto pela Secretaria de Cultura.

Segue a transcrição da Ata da décima sessão da oitava reunião ordinária realizada em 16 de outubro de 1984 - sexta-feira. 
Dr. Zaire Rezende falou primeiro de sua alegria em estar presente no legislativo. Achou um trabalho tremendamente importante o legislativo, embora ele possa parecer enfadonho, monótono ou destituído de sentido. Todos os atos do legislativo têm uma significação muito grande, porque respondem às pequenas necessidades do ser humano. Em nossa administração, temos dois tipos de trabalho. Um trabalho Administrativo e outro político. Através do administrativo procuramos modernizar a nossa administração, porque estamos convictos que a prefeitura não acompanhou o crescimento de Uberlândia. Havia várias áreas sem a atenção necessária. No aspecto político o ponto básico é a democracia, que começa por dentro. Procuramos estabelecer um governo que não é vertical e não é centralizador. É um governo de equipe. A última palavra surge do consenso da discussão. Procuramos estabelecer essa democracia também no relacionamento com o legislativo, através de um profundo respeito para com ele. Nesta democracia com o legislativo, temos procurado atender a todas as solicitações que advém dele, seja de qualquer partido. Democracia também que nunca usamos o decurso de prazo em qualquer projeto enviado ao legislativo, por acharmos que é uma violência contra o mesmo. Dentro dessa democracia, procuramos implantar o que chamamos de democracia participativa. E então, convidamos todos os segmentos da sociedade, para participar do governo, como normalmente apenas as classes dominantes participaram do governo, nós procuramos abrir espaço para que os outros ocupassem. Sabemos que esta proposta é controvertida, sobretudo em relação ao legislativo. (...) Dentro do plano administrativo começamos propondo a criação de algumas novas secretarias que não existiam, com o objetivo de ocuparem áreas que não estavam sendo cobertas pela prefeitura municipal tais como: Secretaria de Agricultura, Secretaria de Cultura, a Secretaria de Saúde foi desmembrada e a Secretaria de Meio Ambiente. (UBERLÂNDIA, Fundo: Câmara Municipal; série: atas; subsérie: atas da Câmara Municipal; datas: 09/1985 à 12/1984; No: 0121)

No documento é enfatizada, no aspecto político, a democracia, já que o governo de Zaire Rezende era de uma equipe, como também procurou atender todas as solicitações que lhes foram feitas. É perceptível que surgiu um espaço para aqueles que nunca tiveram oportunidade de participar do governo. Já em relação ao aspecto administrativo, foi priorizada a criação de diversas secretarias que não eram cobertas pela prefeitura municipal.

Justamente por ter como foco uma ação social visando a participação da população que morava nos bairros, ou seja, aqueles que não se encontravam na elite uberlandense, recebendo assim o rótulo de comunista, já que trabalhava para a classe trabalhadora que residia nos bairros da periferia. Como pode ser visto abaixo na Ata da quinta sessão da décima terceira reunião extraordinária realizada em 21 de dezembro de 1984 - sexta-feira. 
Pedro Matias disse que acha difícil quando o vereador Adriano Bailoni classifica o PMDB de comunista. Para mim ele é grande divulgador do comunismo. Porque, quando alguém trabalha para o povo, é comunista. Então ele o divulga o comunismo, dizendo que ele é bom. Eu gostaria então que ele contasse o quê que o comunismo faz de com para o povo. Eu acho que um projeto desse não tem nada de comunista. Ele tem um fundamento social, mas não de comunismo. Adriano Bailoni pediu a parte para dizer que ele falou que o vereador Geraldo estava usando uma atitude comunista. V. Exa. pegou o bonde andando. Pedro Matias disse

que o edil Adriano de vez em quando classifica de comunista a bancada do PMDB. Se o comunismo for bom como V. Exa. está falando, nós devíamos é ser comunistas mesmo. (UBERLÂNDIA, Fundo: Câmara Municipal; série: atas; subsérie: atas da Câmara Municipal; datas: 09/1985 à 12/1984; No: 0121)

A prioridade do governo Zaire Rezende era construir uma cidade mais humana, como pode ser entendido diante tudo o que foi exposto nessa pesquisa. Resende ainda ressalta que antes não havia a preocupação em facilitar o acesso à leitura para o povo:

Olha, eu acho que foi muito importante, inclusive a grande importância que eu vejo foi a novidade, entende? Nunca tinha se pensado em priorizar essa possibilidade de facilitar o povo a ter acesso à leitura. $\mathrm{O}$ circo foi muito importante, a biblioteca ambulante, entende? E também foi muito importante e a biblioteca municipal tudo o que ela pode oferecer, tudo isso. (REZENDE, 2015, p. 216).

É interessante constatar que as ações da Secretaria Municipal de Trabalho e Ação Social estavam voltadas para a resolução dos problemas sociais e abertas à participação popular, já que o governo priorizou por ser uma administração humanitária, principalmente da população dos bairros mais afastados.

O governo Zaire Rezende afirma nas narrativas que suas ações foram voltadas para o social, para que a cidade tivesse uma administração humana, democrática. A Secretaria de Cultura neste contexto procurou dar espaço para as diversas expressões culturais da cidade e não somente àquelas mais eruditas.

Diante o exposto nesse artigo, podemos concluir que o governo Zaire Rezende iniciou um processo de redemocratização das políticas culturais da cidade, tendo em vista os inúmeros projetos planejados e implantados, preocupados com a leitura que foi uma das reivindicações da população. As políticas culturais chegaram a população de baixa renda com o auxílio da então chamada de democracia participativa, com uma movimentação ativa das associações de moradores de bairros criadas justamente para que seus anseios fossem ouvidos primeiramente e depois sanados. Tanto pelas narrativas dos entrevistados como os documentos pesquisados constatamos que esse governo tentou na medida do possível e com toda a direita torcendo contra, implementar uma política de leitura em diferentes espaços tais como na Biblioteca Pública Municipal "Juscelino Kubitschek de Oliveira" local esse onde foi dado um pontapé inicial para que os projetos visando a cultura e a leitura fossem implantados e chegassem à população de baixa renda que moravam na periferia de Uberlândia, os concursos, a biblioteca itinerante, e tantos outros projetos. 


\section{Referências}

ALEM, João Marcos. Representações coletivas e história política em Uberlândia. História e Perspectiva, Uberlândia: EDUFU, n.4, p.79-102, jan/jun, 1991.

ALVARENGA, Nízia Maria. As associações de moradores em Uberlândia: um estudo das práticas sociais e das alterações nas formas de sociabilidade, 1988. Dissertação (Mestrado em Ciências Sociais). Programa de Estudo Pós-graduados em Ciências Sociais da Pontifícia Universidade Católica de São Paulo, São Paulo.

ALVARENGA, Nízia Maria. Movimento popular, democracia participativa e poder político. História e Perspectiva, Uberlândia: EDUFU, n.4, p.103.29, jan/jun, 1991.

ARQUIVO PÚBLICO MUNICIPAL DE UBERLÂNDIA. Jornal Primeira Hora. 23/12/1983.

FEIJÓ, Martin Cezar. O que é política cultural. São Paulo: Brasiliense, 1985.

FERREIRA, Vanessa de Souza. Creches Comunitárias e Democracia Participativa: novas perspectivas à infância uberlandense (1983-1988), 2010. Dissertação (Mestrado em Educação) - Programa de Pós-Graduação em Educação da Universidade Federal de Uberlândia, Uberlândia.

JESUS, Wilma Ferreira de. Poder Público e Movimentos Sociais: Aproximações e Distanciamentos /Uberlândia - 1982-2000. Dissertação (Mestrado) - Universidade Federal de Uberlândia, Uberlândia, 2002.

JESUS, Wilma, Ferreira de. Poder público e movimentos sociais - novos ideais - velhas práticas - Uberlândia 1982-2000. Cadernos de Pesquisa do CDHIS (UFU), v. 39, p. 31-44, 2008. Disponível em: 〈http://www.seer.ufu.br/index.php/cdhis/article/view/2252〉. Acesso em $13 / 12 / 2015$.

MEIHY, José Carlos Sebe Bom. Definindo história oral e memória. In: Cadernos CERU, $\mathrm{n}^{\circ} 5$ série 2, 1994. Comunicação apresentada no $1^{\circ}$ Encontro Nacional de História Oral. São Paulo, 19 de abril de 1993.

PORTELLI. Tentando aprender um pouquinho: algumas reflexões sobre a ética na história oral. Projeto História. São Paulo, n. 15, abr./1997.

REZENDE, Zaire. Proposta para Ação do Governo Municipal. Uberlândia, 1982.

ROMERO, Márcia Cicci. Política de incentivo à leitura no governo Zaire Rezende 1983 1988, 2016. Dissertação (Mestrado em Educação) - Programa de Pós-Graduação em Educação da Universidade Federal de Uberlândia, Uberlândia.

SANTOS, Carlos Meneses Sousa. Democracia participativa na Uberlândia dos anos de 1980 uma "prece democrática". IN: Anais do XVIII Encontro Regional de História - O historiador e seu tempo. ANPUH/SP - UNESP/Assis, 24 a 28 de julho de 2006. Disponível em:<http://www.anpuhsp.org.br/sp/downloads/CD\%20XVIII/pdf/PAINEL\%20PDF/Carlos\%2 0Meneses\%20Sousa\%20Santos.pdf >. Acesso em 15/12/2015. 
SANTOS, Carlos Meneses Sousa; CARDOSO, Heloísa Pacheco. Democracia Participativa em Uberlândia - significados das experiências dos moradores do bairro Nossa Senhora das Graças. Horizonte científico, p.1-30, número 1, volume 1, 2007. Disponível em: < http://www.seer.ufu.br/index.php/horizontecientifico/article/view/3838/2843)>. Acesso em 10/12/2015.

SILVA, Alex Marciel da. Uma contribuição da geografia eleitoral: a espacialização do voto no $1^{\circ}$ turno das eleições majoritárias do ano de 2000 em Uberlândia-MG. Dissertação (Mestrado) - Universidade Federal de Uberlândia, Programa de Pós-Graduação em Geografia. Uberlândia, 2004.

SOARES, Beatriz Ribeiro. Habitação e Produção do Espaço em Uberlândia. São Paulo: EDUSP, 1988.

SOUZA, Vilma A. de; História da política local e sua interface com a gestão educacional. In: X jornada do HISTEDBR, História da Educação: Intelectuais, Memória e Política? 2011, Vitória da Conquista-BA. Jornada HISTEDBR, 2011.

THOMPSON, Paul. A voz do passado. Trad. Lólio Lorenço de Oliveira. 3. ed. São Paulo: Paz e Terra, 1988.

TORRES, Maria José de Oliveira. Acervo pessoal: Folder, Política Cultural da Secretaria Municipal de Cultura, Uberlândia, 1987.

UBERLÂNDIA. Prefeitura Municipal de Uberlândia/MG. Fundo: Câmara Municipal de Uberlândia; série: atas; subsérie: atas da Câmara Municipal; data: 01/1983 à 12/1983; No: 119. Ata da sessão em 18 de abril de $1983 a$.

UBERLÂNDIA. Prefeitura Municipal de Uberlândia/MG. Fundo: Câmara Municipal De Uberlândia; série: atas; subsérie: atas da câmara municipal; data: 01/1983 à 12/1983; №: 119. Ata da segunda sessão da sexta reunião ordinária de 1983 realizada em 17 de agosto de $1983 b$.

Fontes orais:

CARVALHO, Denise. Uberlândia (MG), 22 de abril de 2014. Gravador (31 minutos e 46 segundos). Entrevista concedida a Márcia Cicci Romero.

MENDONÇA, Maria Inês. Uberlândia (MG), 18 de maio de 2015. Gravador (31 minutos e 45 segundos). Entrevista concedida a Márcia Cicci Romero.

REZENDE, Zaire. Uberlândia (MG), 23 de abril de 2015. Gravador (38 minutos). Entrevista concedida a Márcia Cicci Romero.

SILVA, Terezinha Elizabeth da. Uberlândia (MG), 01 de maio de 2015. Gravador (55 minutos e 21 segundos). Entrevista concedida a Márcia Cicci Romero.

TORRES, Maria José de Oliveira. Uberlândia (MG), 25 de maio de 2015. Gravador (1hora, 32 minutos e 27 segundos). Entrevista concedida a Márcia Cicci Romero. 
Notas

${ }^{1}$ FACED/UFU Universidade Federal de Uberlândia.

${ }^{2}$ FACED/UFU Universidade Federal de Uberlândia.

${ }^{3}$ Adriano Bailoni Júnior foi um advogado que atuou como vereador a partir de 1962 até 1988. 